\title{
Heavy air pollution with a unique "non-stagnant" atmospheric boundary layer in the Yangtze River middle basin aggravated by regional transport of $\mathbf{P M}_{2.5}$ over China
}

Chao Yu et al.

Correspondence to: Tianliang Zhao (tlzhao@nuist.edu.cn) and Yongqing Bai (2007byq@163.com)

The copyright of individual parts of the supplement might differ from the CC BY 4.0 License. 
(a)

(b)

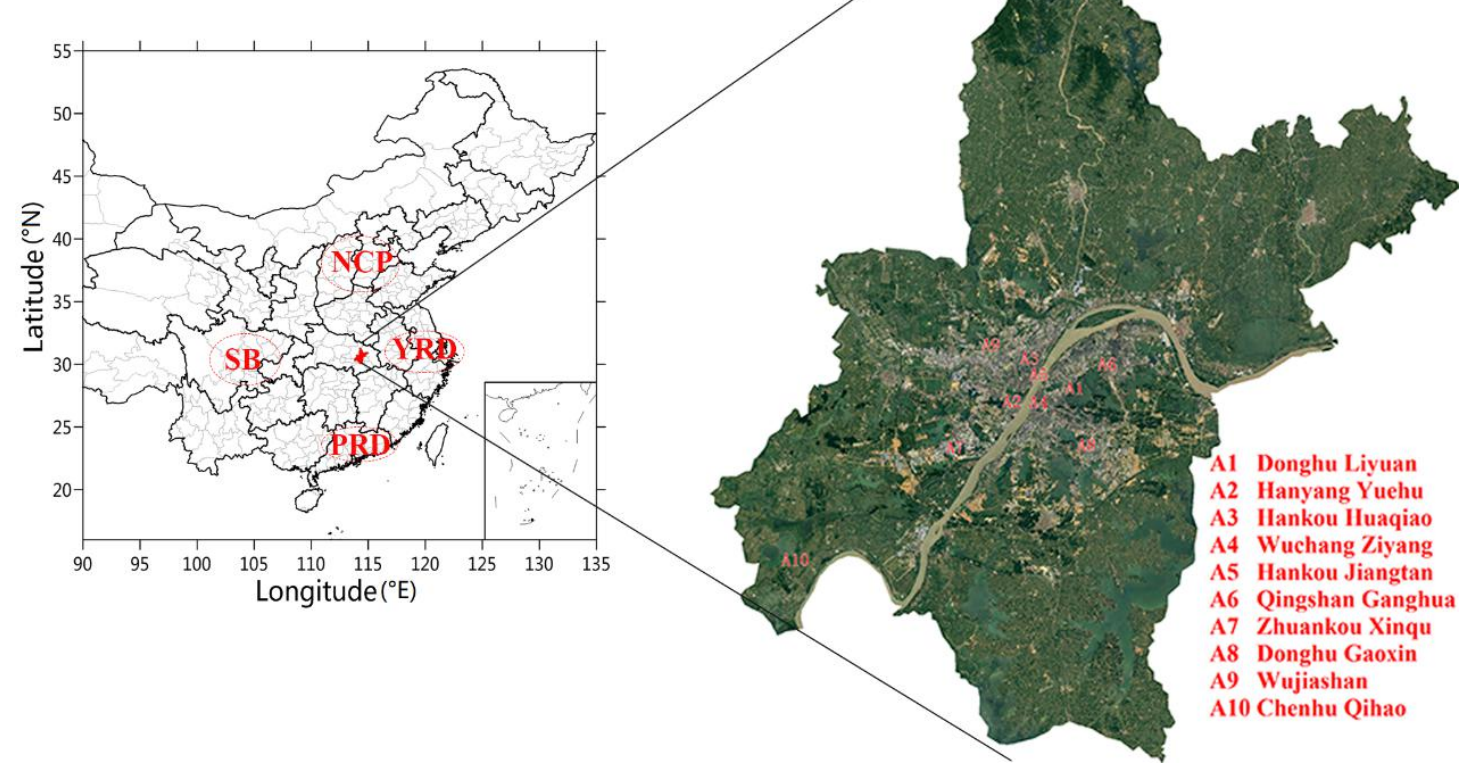

Figure S1. (a) The location of Wuhan (red area) and the major haze pollution regions of NCP, YRD, PRD and SCB in Central and Eastern China as well as (b) geographical locations of 10 sites $(\mathrm{A} 1, \mathrm{~A} 2, \ldots . . ., \mathrm{A} 10)$ for air pollutants measurements over the Wuhan area within the national air quality monitoring network operated by the Ministry of ecology and environmental protection of China (http://www.mee.gov.cn/).

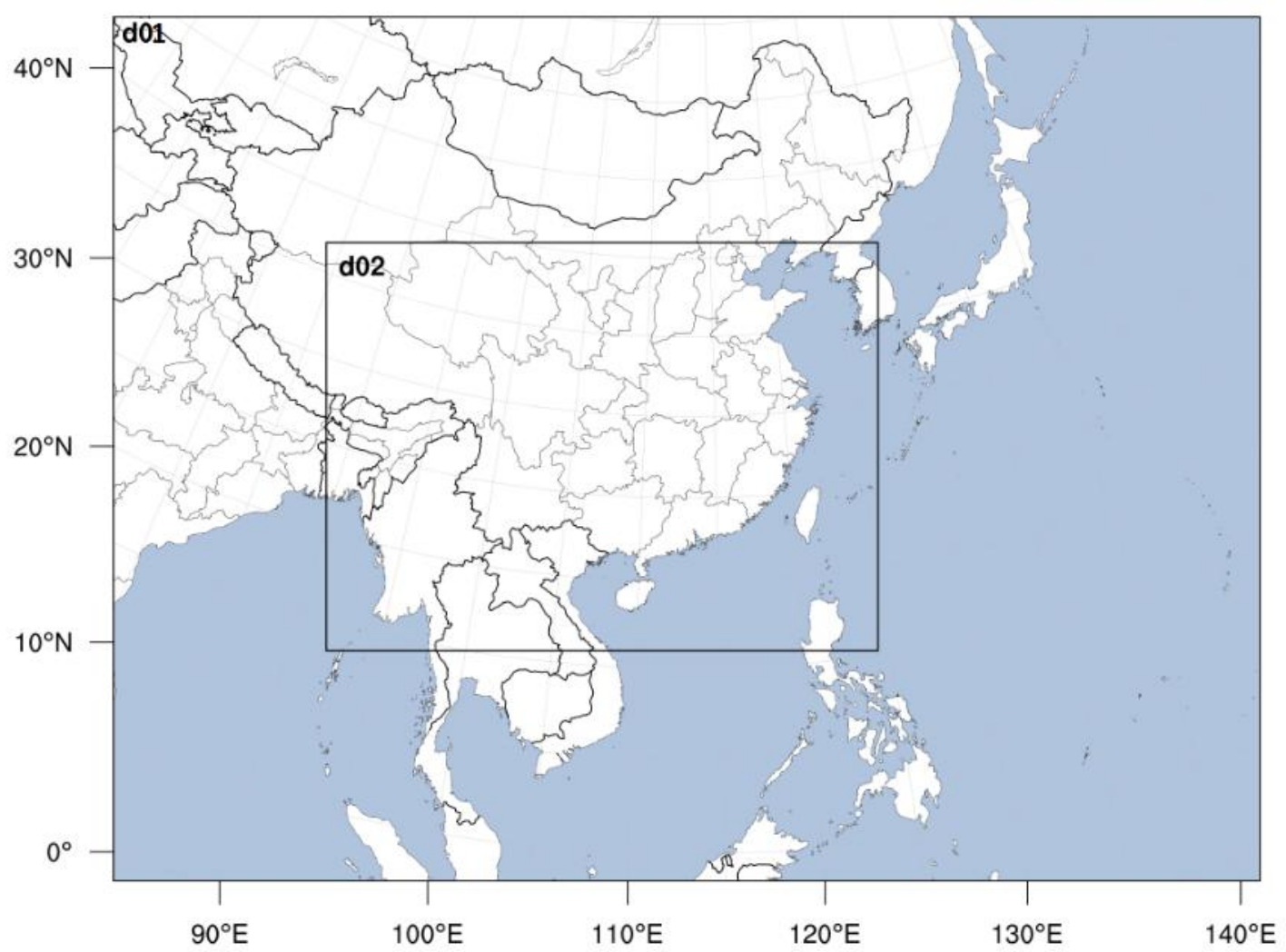

Figure S2. WRF modeling domain for the FLEXPART simulation study. 


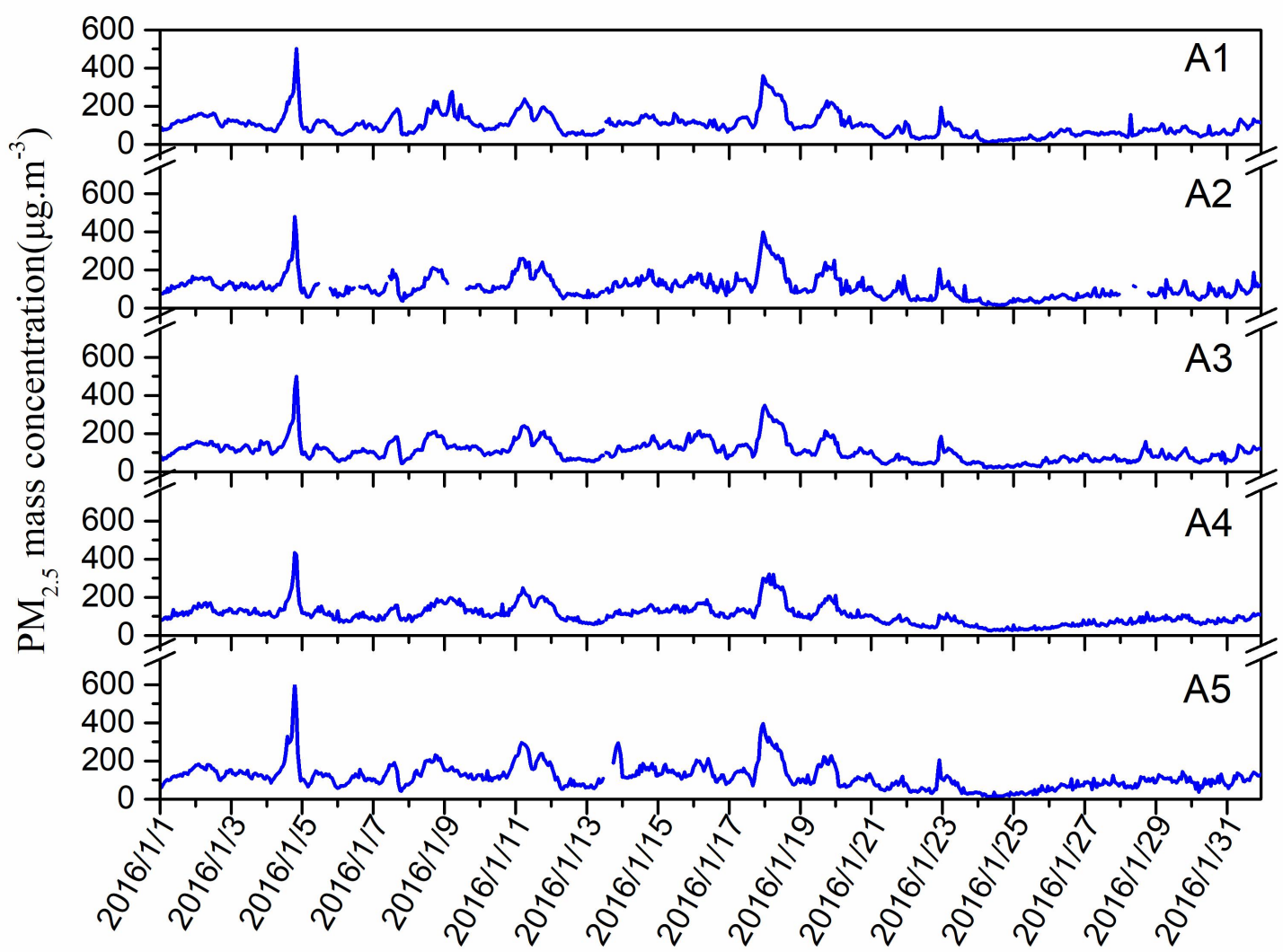

Figure S3. Hourly variations of $\mathrm{PM}_{2.5}$ concentrations $\left(\mu \mathrm{g} \mathrm{m}^{-3}\right)$ in January 2016 at the observational site A1, A2, A3, A4 and A5 (see Fig. 1S) over Wuhan area.

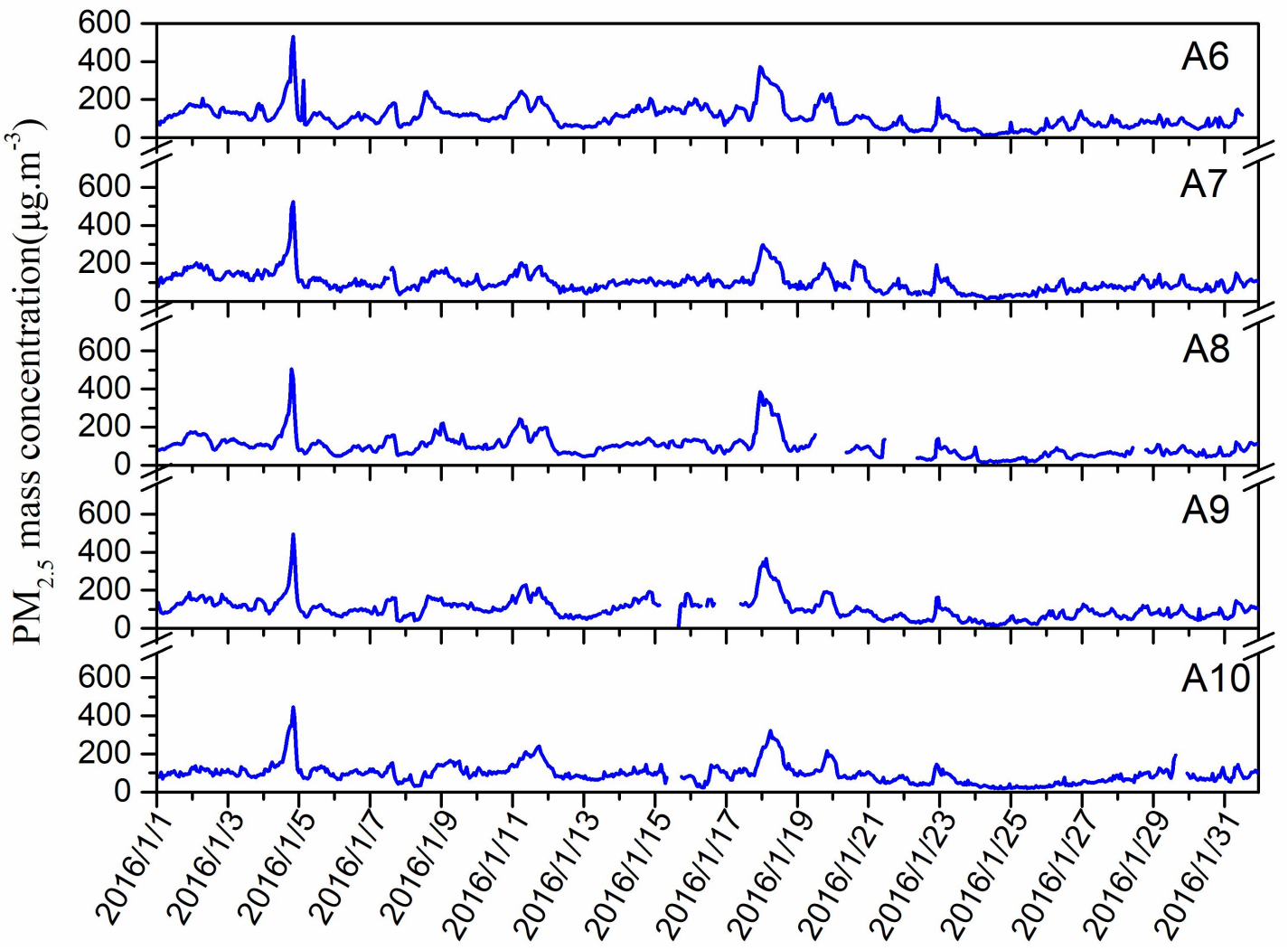

Figure S4. Hourly variations of $\mathrm{PM}_{2.5}$ concentrations $\left(\mu \mathrm{g} \mathrm{m}^{-3}\right)$ in January 2016 at the observational 
site A6, A7, A8, A9 and A10 (see Fig. 1S) over Wuhan area.

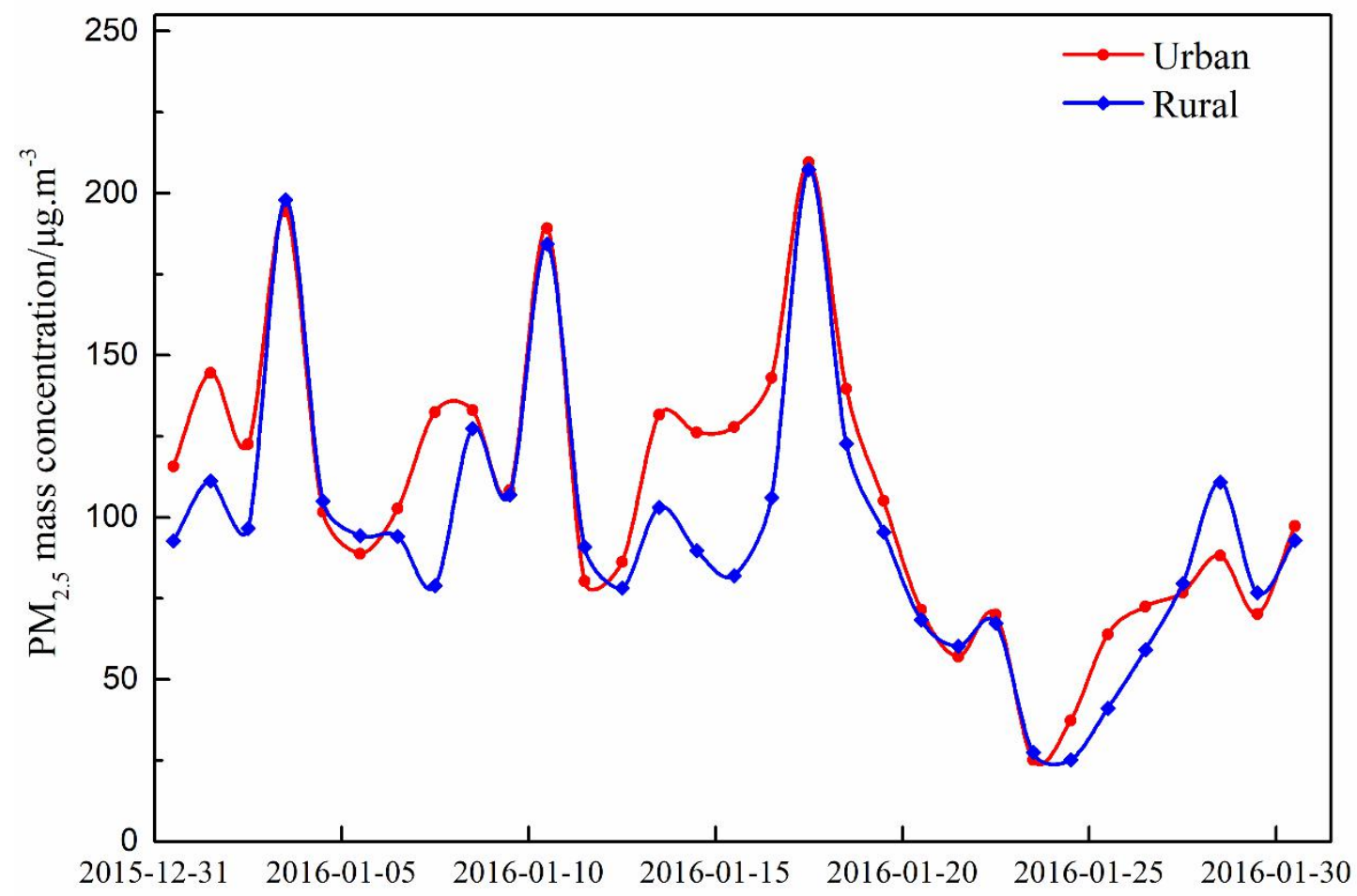

Figure S5. Daily variations of $\mathrm{PM}_{2.5}$ mass concentrations in January 2016 averaged over the urban sites A1, A2,A3,A4, A6, A7,A8 and A9 as well as the rural site A10 (see Fig. S1) in Wuhan area. 